\title{
Gilles Lipovetsky?
}

[ ANA PAULA CAVALCANTI SIMIONI ]

Mestre e doutora em Sociologia da Cultura pela Universidade de São Paulo. Pós-doutora em História da Arte pela Université de Genève (Suiça). Docente do Instituto de Estudos Brasileiros (USP). Pesquisadora nas áreaas de arte, gênero, cultura e poder. Autora de Profissão artista: pintoras e escultoras acadêmicas brasileiras (Edusp/Fapesp, 2008).

E-mail: anapcs@usp.br

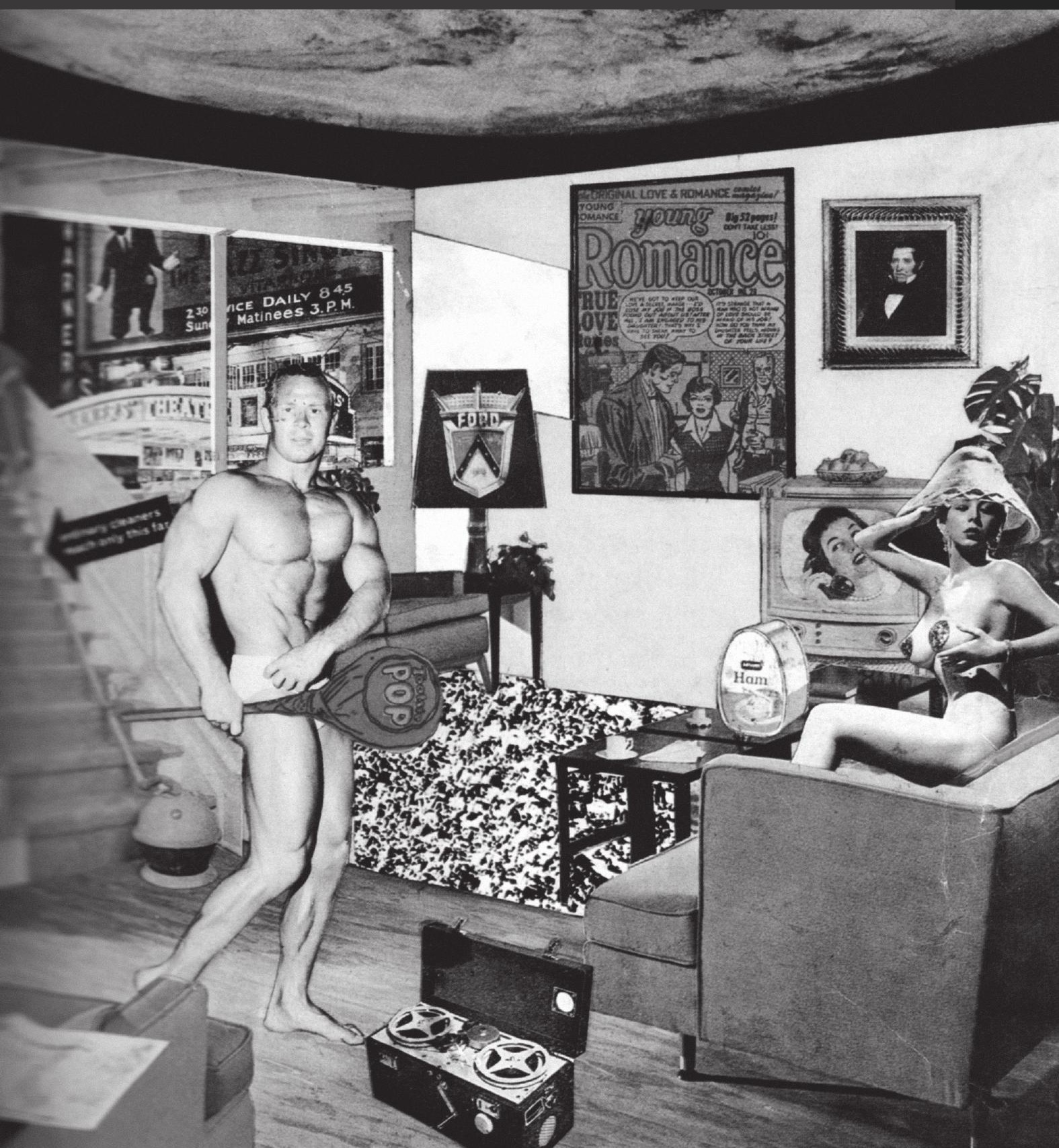


A interrogação da moda exige uma modificação radical de paradigma. Anunciemos esse deslocamento teórico em grandes traços: as reviravoltas perpétuas da moda são, antes de tudo, o efeito de novas valorizações sociais ligadas a uma nova posição e representação do indivíduo em relação ao conjunto coletivo. A moda não é o corolário do conspicuous consumption e das estratégias de distinção de classes; é o corolário de uma nova relação de si com os outros, do desejo de afirmar uma personalidade própria que se estruturou ao longo da segunda Idade Média nas classes superiores. É porque o papel da representação do indivíduo não foi avaliado em seu justo valor que as explicações da mudança de moda permanecem tão pouco convincentes. Longe de ser um epifenômeno, a consciência de ser indivíduos com destino particular, a vontade de exprimir uma identidade singular, a celebração cultural da identidade pessoal foram uma 'força produtiva', o próprio motor da mutabilidade da moda. Para que aparecesse o impulso das frivolidades, foi preciso uma revolução na representação das pessoas e nos sentimentos de si, modificando brutalmente as mentalidades e valores tradicionais; foi preciso que se desencadeassem a exaltação da unicidade dos seres e seu complemento, a promoção social dos signos da diferença pessoal. ${ }^{1}$

Richard Hamilton 0 que exatamente torna os lares de hoje tão diferentes, tão atraentes?, 1964. Colagem. Kunsthalle Tübingen, coleção Prof. Dr. Georg Zundel.

Fonte: McCarthy, David. Art Pop. São Paulo: Cosac Naify, 2002, p. 7.
Resenhar a produção de Gilles Lipovetsky, autor prolifero, que escreve com desenvoltura sobre temáticas diversas, é tarefa árdua. Para não sucumbir ao tratamento superficial de suas ideias, tão disseminadas e capitais para a área de moda, pareceu-me mais apropriado analisar um de seus mais emblemáticos livros: 0 império do efêmero.

Publicado em finais dos anos 1980 na França, 0 império do efêmero: a moda e seu destino nas sociedades modernas, nasceu clássico, e com a pretensão de sê-lo. Explico: o livro é extremamente ambicioso. De um lado, trata-se de uma interpretação histórica de longo alcance, que aborda o desenvolvimento da moda desde seu nascimento, em fins da Idade Média, até a contemporaneidade. De outro lado, pretende estabelecer uma interpretação teórica original capaz de superar toda a tradição de estudos anteriores (de Tarde, passando por Simmel, Veblen até chegar a Bourdieu), os quais, segundo o autor, podem ser enquadrados em uma mesma escola analítica, a das "teorias da distinção".

Segundo Lipovetsky, tal esquema explicativo dominante entende as mudanças da cultura material a partir da tese de que são os grupos intermediários e inferiores que, desejando se equiparar aos superiores, adotam seus hábitos e estilos de vida; uma vez que tais elementos se generalizam, os grupos mais bem posicionados na hierarquia social os abandonam, adotando novos sinais capazes de diferenciá-los dos estratos inferiores. Ou seja, a transitoriedade da moda seria explicável pelo desejo de imitação e de distinção entre os grupos sociais. 0 autor destoa do coro analítico propondo uma nova interpretação sobre a moda: a de que esta é fruto não da dialética da distinção e da pretensão de classes (tão bem analisada por Pierre Bourdieu, espécie de interlocutor privilegiado ao longo de todo o livro), 

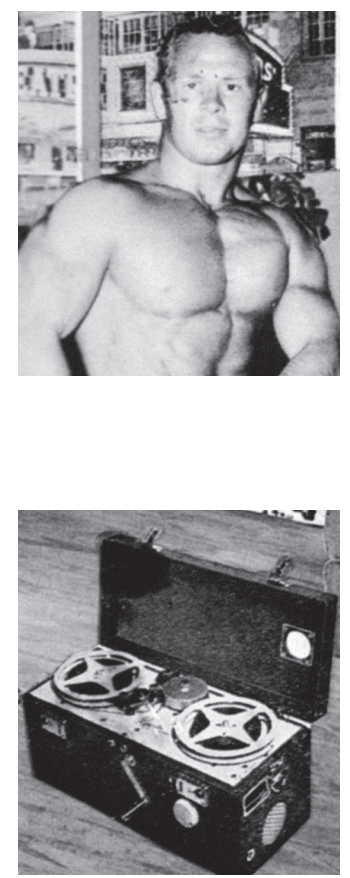

$[40]$
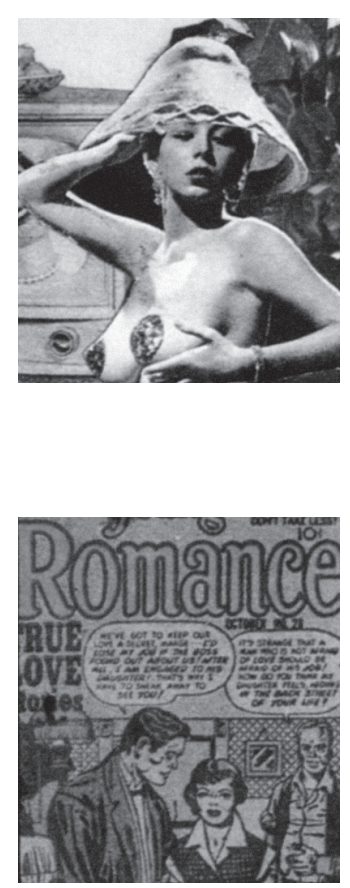

mas sim dos valores e significações modernas, particularmente o culto ao novo e a importância conferida à individualidade de cada ser humano, que, ao seu ver, permitiram o nascimento da moda.

Para comprovar sua teoria, Lipovetsky redesenha a história do desenvolvimento da moda, pinçando exemplos históricos e interpretações convenientes à sua teoria. Sua narrativa não é nada neutra, pelo contrário, o modo com que descreve o nascimento da moda até sua vigência totalitária na sociedade contemporânea está imbuído de uma visão evolutiva sobre o fenômeno, em que figura uma crença na moda como um "processo civilizador". Infelizmente, não poderei, nestas breves linhas, comentar pormenorizadamente o uso intencional dos exemplos históricos com vistas à comprovação das teorias, partindo das análises para os fatos, o que colige com os procedimentos comuns às práticas dos historiadores profissionais. Mas fica aqui como aviso. Vamos à obra.

0 livro parte de uma interessante definição de moda, que abarca, mas transcende, a cultura das roupas, trata-se de um "dispositivo social caracterizado por uma temporalidade particularmente breve" (LIPOVETSKY, 2002, p. 24). Moda é o reino do efêmero sistemático, do domínio do gosto pela novidade enquanto um princípio constante e regular que organiza o estilo de vida dos indivíduos e grupos sociais. Nesses termos, a moda não é uma prática trans-histórica e universal, não existe em todas as sociedades e culturas, é sim uma experiência que desponta em um momento e espaço específicos: o Ocidente Moderno.

A moda teria se originado em finais do século XIV, em algumas sociedades ocidentais (como a França, a Itália e a Espanha), nas quais as particularidades de suas configurações nacionais, estatais e econômicas favoreceram a emergência de grupos sociais específicos, como os comerciantes, os burgueses ou os "novos ricos" que, ciosos por demonstrarem sua posição ascendente, transgrediram as normas estatutárias e se puseram a copiar os trajes da nobreza. Segundo a análise, a moda teria contribuído para promover uma quebra das distâncias sociais, fomentando certa igualdade nas aparências.

Ainda que, desde esse início até às sociedades de corte, sobretudo as dos Setecentos, a prática de adotar novos trajes, penteados etc. fosse um elemento restrito às elites, fomentado pela rivalidade entre as classes e frações de classe, para o autor deixava entrever sua função democrática. Mais do que um emblema de distinção, Lipovetsky interpreta-a como um impulso para inovar, igualar, transgredir ou, em última instância, permitir que o indivíduo realize-se, liberando-se dos desígnios impostos pela tradição. Ao seu ver, a moda desempenhou historicamente uma função primordial: contribuiu para liberar os individuos das regras e dos cerceamentos impostos pelos costumes, ao valorizar as escolhas individuais (e não mais as do grupo) e ao 
legitimar o presente como tempo de realização, e não mais a autoridade imemorial do passado (LIPOVETSKY, 2002).

A segunda fase da moda abarca desde meados do século XIX até meados do século XX. A "moda de cem anos" é o momento em que se cria um sistema de moda, alicerçado em dois polos: a alta-costura $x$ a confecção industrial. Nesse momento, por meio do estabelecimento de um calendário atrelado às estações, bem como da centralização da legitimidade da criação nas mãos de uma nova e emblemática figura, os costureiros, a moda se organiza e se normatiza. Desde Worth, como mostra Lipovetsky, a promoção social do costureiro (que não mais divide com o cliente a decisão sobre a produção), que de artesão torna-se artista, esteve associada à própria autonomização da moda. Esta, de despercebida, foi paulatinamente tornando-se assunto central, comentada por escritores, retratada por artistas e caricaturistas, e objeto de inúmeras revistas surgidas no período.

Esse sistema de longa duração articulado em torno da alta-costura é eivado de ambiguidades. De um lado, essa estética do benfeito, do luxuoso, do único, do requinte, prolonga um ethos aristocrático da fase anterior, no limite, traduzindo uma busca por distinção e classe. De outro lado, para o autor, é um elemento democratizador. A alta-costura, com sua abrangência internacional, libertou a moda de suas características locais, regionais. E mais do que isso, ela democratizou o acesso à distinção e ao bom gosto, até então um privilégio dos estamentos privilegiados da sociedade. A moda, em seu entender, trouxe novos modos de individualizar as aparências, opondo-se à estandartização da sociedade de massas que surgia nas metrópoles modernas. Destaca ainda, lembrando as criações de Chanel, o desenvolvimento de um novo luxo, menos apegado a sinais ostentatórios e, no limite, mais democrático.

Com a consolidação do prêt-à-porter nos anos 1960 e 1970, a moda finalmente teria se depurado de quaisquer emblemas de classe e distinção, ainda presentes no sistema da alta-costura. Nessa terceira etapa do processo, "a moda aberta" se caracterizaria pela ausência de um centro difusor da criação legítima; não se pode mais falar em moda, mas sim "modas", uma vez que os grupos juvenis, as minorias, os estilos de vida dos vários grupos urbanos teriam conquistado o direito pleno de afirmação. Estamos, para o autor, diante do período democrático por excelência. 0 culto pelo novo, pelo direito individual de escolha, pela busca do prazer, do consumo, em uma sociedade hedonista, haveria se imposto definitivamente. A nova sociedade é então pintada como mais tolerante do que as demais, uma vez que aceita as escolhas dos indivíduos; uma sociedade aberta, maleável, sem espaço para as tiranias, as opressões. $E_{1}$ finalmente, chegaríamos ao fim do processo: a era da "moda consumada". Consumada porque a lógica de produção da moda, a valorização constante do novo, a efemeridade como o tempo pretendido, o consumo individual como espaço de realização, teria se imposto nas mais diversas áreas da cultura e do pensamento. De assunto menor, frívolo, tornou-se o modo central de viver, e de pensar, na sociedade contemporânea: as próprias ideologias perderam sua força e rigidez, sendo rapidamente incorporadas e trocadas pelos indivíduos das gerações mais recentes, o que faz deles seres menos convictos e "sérios", mas, para o autor, mais tolerantes com as outras formas de ação e pensamento.

Aqui valeria ressaltar o quanto o autor procura distinguir-se das teses de Pierre Bourdieu que, no célebre texto 0 costureiro e sua grife ${ }^{2}$, analisou com propriedade a alta-costura como um elemento decisivo dos habitus ${ }^{3}$ comuns a frações das elites francesas em suas lutas simbólicas por distinção. Bourdieu demonstra ainda o quanto a crise da alta-costura não implicou o fim das distinções mas, ao contrário, uma nova reestruturação de suas maneiras de aparecer, doravante centradas no "corpo" como o espaço por excelência das distinções. 0 corpo belo, "naturalmente benfeito", é talvez a forma mais cruel de todas as afirmações de classe, uma vez que "naturaliza" seus significados expressivos. Afinal, ser belo, ter o corpo "da moda" não é mais algo que se possa "comprar"; eis o que a valorização da "beleza natural e jovem" trouxe consigo.

Ao ler 0 império do efêmero é impossivel não se indagar sobre qual sociedade ou grupo social o autor está falando: todas as sociedades contemporâneas oferecem a seus cidadãos essa possibilidade quase infinita de consumo? 0 consumo é de fato tão 
democrático assim? É tão inclusivo? E todos os indivíduos são dotados da capacidade de escolher livremente nesse "supermercado de estilos" que lhe é oferecido? Os estilos adotados são de fato igualmente válidos? Não há distinções e hierarquias no universo da moda? Todos os corpos são iguais? Todas as cores de pele valem o mesmo? Então, uma negra imigrada africana, rechonchuda, vestida como rapper será igualmente tratada como uma senhora branca, vestida com um alinhado manteau branco, num bistrô de St. Germain?! Que assim fosse! Isso para ficar no mínimo. As investidas políticas presentes no livro são ainda mais discutíveis: afirmar que o mundo hoje está livre do totalitarismo e do racismo após as experiências da Guerra da Bósnia e de tudo o que o 11 de Setembro trouxe consigo é bastante complicado. O.k.! Ambos os fatos são posteriores ao livro, o autor não tinha como saber. Por isso, sempre é bom lembrar: as ciências humanas não devem ser proféticas. E reside aí uma das grandes fragilidades do livro: a análise histórica está do início ao fim marcada por um prisma evolutivo, como se o desenvolvimento da moda significasse um processo de conquista, cada vez maior, de graus de liberdade, individualidade, felicidade e democracia. É quase inescapável a sensação de que a contemporaneidade vivencia o "fim da história", constitui o ápice de um processo de perfectibilidade!

A pretensão da obra é seu ponto forte e também seu ponto fraco. 0 livro propõe uma nova teoria para compreensão da moda, que diverge das teorias anteriores, marcadas pela tese de que a moda se explicaria pelas teorias da imitação e distinção entre os grupos sociais. Além de ser uma obra corajosa, parece trazer um novo olhar talvez mais apto, mais sensivel para compreender o que aconteceu com o mundo a partir dos anos 1960, com a crise da alta-costura. Vale notar, ainda, os muitos insights temáticos levantados pelo livro (como a história do jeans, as distinções entre moda e gênero ou as relações entre moda e mídias) que podem fomentar numerosos projetos de investigação. No entanto, para sustentar sua teoria, o autor faz um uso demasiadamente livre da história, dos dados estatísticos, do retrato do que considera ser a sociedade contemporânea. Trata-se de um ensaio sedutor, mas metodologicamente frágil. E sobretudo: as correlações entre moda e sistema social são interpretações tão otimistas da sociedade contemporânea que, por vezes, somos tentados a perguntar: de que mundo este homem está falando? Do limitado universo dos quartiers chics de Paris?! Mais do que um retrato real da sociedade contemporânea, o livro é um esboço de como esta sociedade gostaria de ser e de se ver.

\section{NOTAS}

[1] LIPOVETSKY, Gilles. 0 império do efêmero: a moda e seu destino nas sociedades modernas. São Paulo: Companhia das Letras, 2002, p. 59.

[2] BOURDIEU, Pierre. 0 costureiro e sua grife: contribuição para uma teoria da magia. In: produção da crença: contribuição para uma economia dos bens simbólicos. São Paulo: Zouk, 2004. A respeito da importância do texto e do autor para a área de moda, consultar também: SIMIONI, Ana Paula Cavalcanti. Por que ler... Pierre Bourdieu? dObra[s], São Paulo, Estação das Letras e Cores, v. 2, no 3, p. $18-21$, jun. 2008

${ }^{[3]}$ De acordo com Bourdieu, o habitus é um sistema gerador (de práticas, gostos, valores, apreciações e classificações estéticas etc.) adquirido pelos indivíduos ao longo do tempo, interiorizado de forma permanente. Permite que se compreenda o modo com que as ações individuais tendem a se adequar às expectativas e aos valores presentes nos grupos aos quais esses fazem parte, mas sem cair num determinismo absoluto. Nesse sentido é diverso do hábito, que é considerado espontaneamente repetitivo, mecânico, automático; totalmente reprodutivo. 0 conceito de habitus pretende dar conta da possibilidade da ação, da criação, da inovação dos indivíduos em suas práticas, mas evitando dois perigos: por um lado a crença na liberdade irrestrita dos sujeitos e, por outro, a visão de que todas as suas ações são determinadas por sua situação social (classe, gênero, raça etc.). Para saber mais, veja: BOURDIEU, Pierre. Esboço de uma teoria da prática. In: ORTIZ, Renato. Pierre Bourdieu: sociologia. São Paulo: Ática, 1983. 